\title{
Cut-Off Points of Head, Chest, and Arm Circumferences to Identify Low Birthweight: Meta-Analysis
}

\author{
Eita Goto \\ Department of Medicine and Public Health, Nagoya Medical Science Research Institute, Nagoya, Japan \\ Email: egoto1@nifty.com
}

How to cite this paper: Goto, E. (2017) Cut-Off Points of Head, Chest, and Arm Circumferences to Identify Low Birthweight: Meta-Analysis. Open Journal of Epidemiology, 7, 175-189.

https://doi.org/10.4236/ojepi.2017.72015

Received: February 28, 2017

Accepted: May 15, 2017

Published: May 19, 2017

Copyright $\odot 2017$ by author and Scientific Research Publishing Inc. This work is licensed under the Creative Commons Attribution International License (CC BY 4.0).

http://creativecommons.org/licenses/by/4.0/

(c) (†) Open Access

\begin{abstract}
Background: The cut-off points of newborn anthropometric variables to identify low birthweight (i.e., birthweight $<2500 \mathrm{~g}$ ) have varied between studies or even within the same study. Methods: Meta-analysis was performed to summarize cut-off points in studies judged as good quality based on the Quality Assessment of Diagnostic Accuracy Studies tool (QUADAS). PubMed (MEDLINE) and nine other databases were searched (January, 2015). PubMed related-citations and references of potentially eligible articles and related reviews were also investigated. The Egger test was used to assess publication bias. Results: With respect to head, chest, and arm circumferences, the cut-off points that involved no publication bias could be summarized based on the data from large numbers of newborns $(=21,793,8917$, and 12,912 , respectively) in relatively sufficient numbers of studies ( $=17,15$, and 19 , respectively). The optimal cut-off points to identify low birthweight were $33.0 \mathrm{~cm}(95 \%$ confidence interval [CI], 32.8 - 33.2), $30.4 \mathrm{~cm}$ (95\% CI, 30.3 - 30.6), and 9.3 $\mathrm{cm}$ (95\% CI, 9.1 - 9.4) for head circumference, chest circumference, and arm circumference, respectively. The summarized cut-off point of birth height, i.e., $47.2 \mathrm{~cm}$ (95\% CI, 46.7 - 47.7), used to identify low birthweight involved publication bias $(n=13)$. Conclusion: The cut-off points were determined to identify low birthweight using head, chest, and arm circumferences.
\end{abstract}

\section{Keywords}

Anthropometry, Infant, Meta-Analysis, Newborn, Low Birth Weight

\section{Introduction}

Low birthweight (i.e., birthweight $<2500 \mathrm{~g}$ ) is a major determinant of newborn mortality and morbidity [1]. Rapid, inexpensive, reliable, and simple means for 
early diagnosis of low birthweight are required to provide immediate and appropriate care for such infants. Infants are sometimes born at home or other places outside hospitals not only in developing countries but also in developed countries. Scales, as sensitive to one $\mathrm{g}$ as those used in hospitals, specifically designed to weigh infants are unavailable at these locations. The measuring tape to measure birth height, head, arm, and chest circumferences, etc., would be a better substitute for such scales and are much cheaper and more portable than the scales. Evidence based on only good quality studies included in a previous metaanalysis was provided to evaluate the diagnostic performance of newborn anthropometric variables for prediction of low birthweight [2]. It was concluded that thigh circumference or foot length ( $n=6$ or 8 , respectively) does not show a satisfactory diagnostic accuracy, but chest or arm circumferences $(n=25$ or 30 , respectively) have a high accuracy in predicting low birthweight in developing countries. On the other hand, other variables including birth height could not be evaluated because there were low numbers of studies. However, the cut-off points of the evaluated variables have varied between studies or even within the same study.

A meta-analysis including the good quality studies was performed to estimate the cut-off points of newborn anthropometric variables to identify low birthweight.

\section{Materials and Methods}

\subsection{Primary Outcome and Selection Criteria}

The primary outcomes were the summarized cut-off points of newborn anthropometric variables to identify low birthweight. The probabilistic model of the simple regression line between birthweight (i.e., $x_{1}, x_{2}, x_{3}, \cdots, x_{n}$ ) vs. newborn anthropometric variable (i.e., $y_{1}, y_{2}, y_{3}, \cdots, y_{n}$ ) is expressed as follows:

$$
y_{i}=\operatorname{intercept}\left(\beta_{0}\right)+\operatorname{slope}\left(\beta_{1}\right) \times x_{i}+\text { residual error }\left(\varepsilon_{i}\right)(i=1,2,3, \cdots, n),
$$

where $n$ is sample number, and $\varepsilon_{i}$ is the normally distributed random error of which the mean is zero. With respect to the least square line (i.e., $y=b_{0}+b_{1} \times x$ ),

$$
\begin{aligned}
& b_{1}=\sqrt{S_{x y} / S_{x x}} \\
& b_{0}=\bar{y}-b_{1} \times \bar{x}
\end{aligned}
$$

where $S$ represents sum of squares or sum of cross products, and $\bar{x}$ and $\bar{y}$ are the means of $x$ and $y$, respectively. In addition, $S_{x x}, S_{x y}$, and $S_{y y}$ can be calculated based on:

$$
\begin{gathered}
\sigma_{x}=\sqrt{S_{x x}} \\
\sigma_{y}=\sqrt{S_{y y}} \\
r^{2}=S_{x y}^{2} /\left(S_{x x} \times S_{y y}\right)
\end{gathered}
$$

where $\sigma$ is the standard deviation (i.e., $\sigma_{x}$ and $\sigma_{y}$ are standard deviations of $x$ and $y$, respectively), and $r$ is the correlation coefficient. With respect 
to the estimate value $\left(\eta_{0}\right)$ corresponding to $x_{0}$ in a summarized simple regression line, 95\% confidence intervals (CIs) were calculated based on:

$$
\begin{gathered}
s\left[\bar{\eta}_{0}\right]=\sqrt{\left(\operatorname{Ve}\left\{1 / n+\left(x_{0}-\bar{x}\right)^{2} / s_{x x}\right\}\right)} \\
\bar{\eta}_{0}-t \times s\left[\bar{\eta}_{0}\right] \leq \eta_{0} \leq \bar{\eta}_{0}+t \times s\left[\bar{\eta}_{0}\right] \\
V e=S_{y y} \times\left(1-r^{2}\right)
\end{gathered}
$$

where $V e$ is residual variance and $\mathrm{t}$ is the 0.975 quantile of the normal distribution. Based on Equations (1)-(5), the inclusion criteria were: (a) studies that provided data on the numbers of apparently healthy newborns, the means and standard deviations of their birthweight and other anthropometric variables, and the correlation coefficients between their birthweight vs. other anthropometric variables; (b) good quality studies (see "Study quality assessment"), and (c) English language studies. The exclusion criteria were; (a) studies in which the standard deviation(s) of birthweight and/or other anthropometric variables were zero because the regression lines could not be calculated based on Equations (1)-(8); (b) poor quality studies (see "Study quality assessment"), and (c) nonEnglish language studies.

\subsection{Search Strategies, Study Selection, and Data Extraction}

PubMed was searched (January 2015)using the following search terms: (weight OR birthweight OR birth-weight OR height OR length OR circumference OR "anthropometric variables" OR anthropometrics) AND (birth OR baby OR babies OR infant OR infants OR neonate OR neonates OR neonatal OR newborn OR newborns OR "new born" OR new-born OR new-borns) AND ("regression line" OR "regression lines" OR "regression equation” OR "regression equations" OR "regression formula" OR "regression formulae" OR "correlation coefficient" OR "correlation coefficients"). The remaining articles after excluding unrelated articles by scanning the titles and abstracts and retrieving the full texts were potentially eligible for inclusion in the analysis. The PubMed related-citations shown by clicking the "See all ..." tabs at the rights sides of the PubMed web pages displaying the potentially eligible articles and the reviews including three meta-analyses [2] [3] [4] and the bibliographic references of the potentially eligible articles and the reviews were also checked. Other databases were searched, i.e., CINAHL, PsycINFO, Wiley Online Library (which offers integrated access to Cochrane Clinical Answers, Cochrane Library and EBM Guidelines: Evidence-Based Medicine and Essential Evidence Plus), ProQuest (which provides ProQuest Health and Medical Complete and ProQuest Dissertations \& Theses Database), Web of Knowledge, Google Scholar, and SciVerse Scopus. Duplicated records were merged, and the literature search was repeated periodically to prevent oversights. No limitation regarding publication periods of the articles was set. Too poor quality studies (see "Study quality assessment") to provide unbiased findings (i.e., internal validity) were excluded. Too low numbers $(<10)$ of studies to provide generalizable findings (i.e., external validity) of the cut-off 
points of some anthropometric variables were also excluded. The numbers of participants, the means and standard deviations of their birthweight and other anthropometric variables, and the correlation coefficients between their birthweight vs. other anthropometric variables were extracted from the studies. These data were categorized into Africa, Asia, Europe, Latin America, the Middle East, North America, or Oceania (study regions), into individual countries, into developing or developed countries, into QUADS score $\geq 10$ or $<10$ (see "Study quality assessment"), and into male or female newborns.

\subsection{Study Quality Assessment}

Study quality was assessed based on the Quality Assessment of Diagnostic Accuracy Studies (QUADAS), a tool for quality assessment of studies of diagnostic accuracy included in systematic reviews, consisting of 14 question items [5]. Study quality was assessed five times, and the most frequent responses were selected as the most appropriate responses to ensure accuracy wherever possible. One and zero were allotted to "yes" responses to the QUADAS items and to other responses (i.e., "no" and "unclear"), respectively. The QUADAS score was defined as the sum of the allotted numbers. The QUADAS scores $\geq 8$ and $<8$ were considered to be good quality and poor quality, respectively.

\subsection{Statistical Analysis}

Stata MP 13/1 (StataCorp LP, College Station, TX, USA) was used for statistical analysis. A meta-analysis was conducted to summarize the cut-off points determined using the regression lines that were applicable to individual studies. A random-effects model and a fixed-effects model were applied to summarize heterogeneous data (i.e., $I^{2} \geq 50 \%$ ) and homogenous data (i.e., $I^{2}<50 \%$ ), respectively [6]. Attempts were made to achieve homogeneity for the heterogenous data by selecting the studies limiting to Africa, Asia, Europe, Latin America, the Middle East, North America, or Oceania, individual countries, developing or developed countries, QUADS score $\geq 10$ or $<10$, and male or female newborns (investigation of heterogeneity sources). The cut-off points were summarized separately depending on the same limitations as investigation of heterogeneity sources, if sufficient numbers of studies $(\geq 3)$ were included (subgroup analysis). The effect of these categorizations on the summarized cut-off points was evaluated to reveal covariates (meta-regression analysis). Meta-regression analysis used a random-effects model based on some occasions where there is residual, or unexplained, heterogeneity [7]. The Egger test was used to assess publication bias (publication bias assessment) [8]. Ethical approval is not required because this study does not use newly human or animal subjects.

\section{Results}

\subsection{Systematic Review}

Twenty five articles were finally included, as shown in the flow diagram of study selection (Figure 1). Two of them [9] [10] represented duplications, and there- 


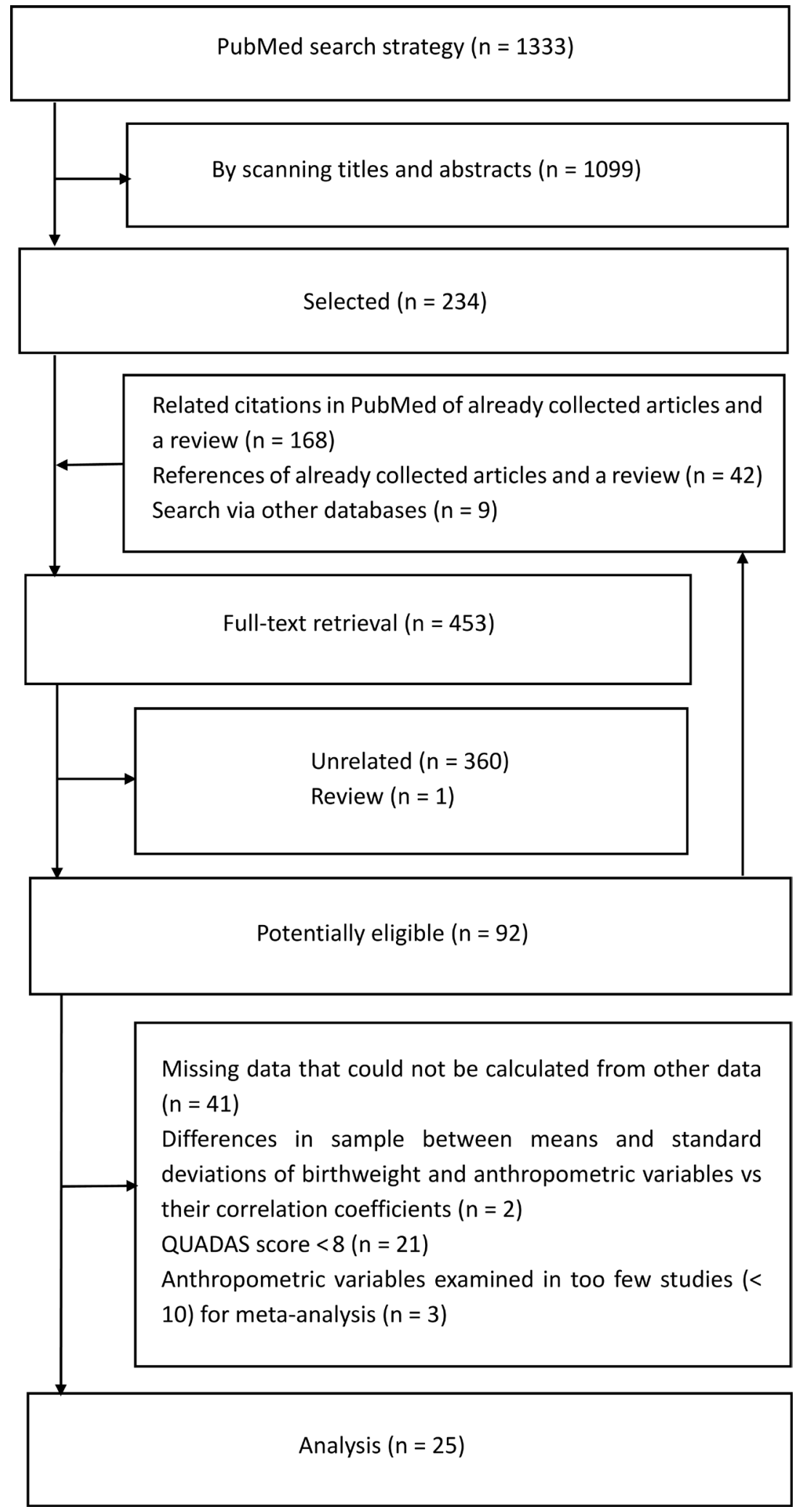

Figure 1. Meta-analysis flow diagram. From 25 articles finally included in this study, the data of a large number of newborns $(=22,358,21,793,8917$, and 12,912) in a sufficient number of studies $(=13,17,15$, and 19$)$ were extracted to summarize the cut-off points of birth height and head, chest, and arm circumferences, respectively, which supported external validity (i.e., the generalizability of the findings). 
Table 1. Summary of included studies.

\begin{tabular}{|c|c|c|c|c|}
\hline Author & Source (Year) & Country & Number of subjects (Category) & Anthropometric variable \\
\hline Arisoy & (1995) J Trop Pediatr, 41, 34-7. & Turkey & 874 (Total) & $\mathrm{BH} \mathrm{HC} \mathrm{CHC}$ \\
\hline \multirow[t]{2}{*}{ Ayatollahi } & (2002) J Trop Pediatr, 48, 245-7. & Iran & 244 (Male) & BH HC CHC MUAC \\
\hline & & & 263 (Female) & BH HC CHC MUAC \\
\hline \multirow[t]{2}{*}{ Ayatollahi } & (2007) Early Child Dev Care, 177, 255-8. & Iran & 5241(Male) & BH HC \\
\hline & & & 5000 (Female) & $\mathrm{BH} \mathrm{HC}$ \\
\hline Bhatia & (1984) Indian Pedatr, 21, 833-8. & India & 341 (Total) & BH HC CHC MUAC \\
\hline Das & (2005) Bangladesh Med Res Counc Bull, 31, 1-6 & Bangladesh & 560 (Total) & BH HC CHC MUAC \\
\hline \multirow[t]{3}{*}{ De Vaquera } & (1983) J Trop Pediatr, 29, 167-74. & Guatemala & 823 (Total) & BH MUAC \\
\hline & & & 820 (Total) & $\mathrm{HC}$ \\
\hline & & & 768 (Total) & $\mathrm{CHC}$ \\
\hline Dhar & (2002) J Health PopulNutr, 20, 36-41. & Bangladesh & 1028 (Total) & BH HC CHC MUAC \\
\hline Dusistin & (1991) Am J Public Health, 81, 1201-5. & Thailand & 402 (Total) & BH CHC MUAC \\
\hline Elizabeth & (2013) BMC Pediatr, 13, 54. & Uganda & 706 (Total) & HC CHC MUAC \\
\hline Ezeaka & (2003) Niger Postgrad Med J, 10, 168-78. & Nigeria & 788 (Total) & BH HC MUAC \\
\hline Figueira & (2004) Sao Paulo Med J, 122, 53-9. & Brazil & 131 (Total) & MUAC \\
\hline Hossain & (1994) Indian J Pediatr, 61, 81-7. & Egypt & 148 (Total) & MUAC \\
\hline Huque & (1991) Indian J Pediatr, 58, 223-31. & Bangladesh & 217 (Total) & CHC MUAC \\
\hline \multirow[t]{2}{*}{ Illingworth } & (1971) Acta PediatrScand, 60, 333-7. & UK & 50 (Male) & $\mathrm{HC}$ \\
\hline & & & 56 (Female) & $\mathrm{HC}$ \\
\hline Khanam & (1990) Bangladesh Med J, 19, 45-50. & Bangladesh & 206 (Total) & MUAC \\
\hline Mohan & $\begin{array}{l}\text { (1991) Indian Pediatr, 28, 1299-304. } \\
\text { (1990) Indian Pediatr, 27, 43-51. }\end{array}$ & India & 2925 (Total) & BH MUAC \\
\hline $\mathrm{Ndu}$ & (2014) Ital J Pediatr, 40, 81. & Nigeria & 511 (Total) & $\mathrm{CHC}$ \\
\hline Olusanya & (2010) J Child Health Care, 14, 386-95. & Nigeria & 3869 (Total) & $\mathrm{BH} \mathrm{HC}$ \\
\hline Pomeroy & (2014) PLoS One, 9, e105108. & Australia & 1270 (Total) & HC CHC MUAC \\
\hline Rustagi & (2012) Asia Pac J Public Health, 24, 343-51. & India & 283 (Total) & HC CHC MUAC \\
\hline Sasanow & (1986) J Pediatr, 109, 311-5. & USA & 204 (Total) & MUAC \\
\hline Shajari & (1996) Acta MedicaIranica, 34, 43-5. & Iran & 1050 (Total) & CHC MUAC \\
\hline Sood & (2002) Indian Pediatr, 39, 838-42. & India & 1272 (Total) & MUAC \\
\hline Sreeramareddy & (2008) BMC Pediatr, 25, 8-16. & Nepal & 400 (Total) & $\mathrm{HC} \mathrm{CHC}$ \\
\hline
\end{tabular}

BH, birth height; BW, birthweight; CHC, chest circumference; HC, head circumference; MUAC, mid-upper arm circumference.

fore they were integrated into one data source (Table 1). More than one study was extracted from one article that used more than one anthropometric variable and/or more than one population. Therefore, a total of 64 studies in Africa, Asia, Europe, Latin America, the Middle East, North American, and Oceania were initially extracted from these 25 articles (Table 1 ). Thirteen studies with 22,358 newborns, 17 studies with 21,793 newborns, 15 studies with 8917 newborns, and 19 studies with 12,912 newborns were included to summarize the cut-off points of birth height and head, chest, and arm circumferences, respectively. The cut-off points of other anthropometric variables, such as abdominal, calf, and 
thigh circumferences, and foot length, were not summarized, because there were too low numbers $(<10)$ of good quality (i.e., QUADAS score $\geq 8)$ studies $(n=3$, 2,6 , and 4, respectively) [11]-[25]. Longer black and gray bars (i.e., more "yes" and "unclear" responses) relative to shorter white bars (i.e., fewer "no" responses) in Figure 2 indicate the overall good quality of the studies, which supported internal validity (i.e., the findings were subject to no serious bias).

\subsection{Meta-Analysis}

Table 2 shows the summarized cut-off points of birth height and head, chest, and arm circumferences in the total population and subgroup (meta-analysis and subgroup analysis). Almost all of the data were heterogeneous $\left(I^{2}=73.0 \%-100 \%\right)$. Homogeneity was limited to the data used to summarize the cut-off points of head circumference in Europe $\left(I^{2}=0.0 \%\right)$ (investigation of heterogeneity sources). The summarized cut-off points of birth height and head, chest, and arm circumferences in the total population were similar to those calculated based on individual studies (Figure 3) and those in all subgroups (Table 2). Study region or country vs. other regions or countries, developing vs. developed countries, QUADAS score $\geq 10$ vs. $<10$ or males vs. females was not shown to be a covariate $(P=0.09-1.00)$ (Table 2$)$ (meta-regression analysis). No publication bias was detected in the summarized cut-off points of head, chest, or arm circumference in the total population $(P=0.05-0.82)$, but publication bias was detected in the summarized cut-off point of birth height in the total population $(P=0.03)$ (publication bias assessment).

\section{Discussion}

\subsection{Main Findings}

This is the first meta-analysis to summarize the cut-off points of anthropometric variables to identify low birthweight. This meta-analysis provided the optimal cut-off points of head, chest and arm circumferences to identify low birthweight (Table 2). These cut-off points did not involve publication bias. The summarized cut-off point of birth height involved publication bias, and therefore it could not be recommended as the optimal cut-off point. The findings may be generalizable (i.e., external validity), because head, chest, and arm circumferences were measured on large numbers of newborns $(=21,793,8917$, and 12,912 , respectively) in relatively sufficient numbers of studies $(=17,15$, and 19 , respectively) that were also extracted from relatively sufficient numbers of articles $(=14,14$, and 19, respectively). Furthermore, there were no studies in which the spectrum of participants was not clearly representative of those that would receive the test in practice (Figure 2). In addition, heterogeneity may suggest that various populations were included. The findings are also unlikely to be seriously affected by bias (i.e., internal validity), because only good quality (i.e., QUADAS score $\geq 8$ ) studies were included. This reflects that the numbers of "yes" or "unclear" responses to the QUADAS items were greater than those of "no" responses (Figure 2). 


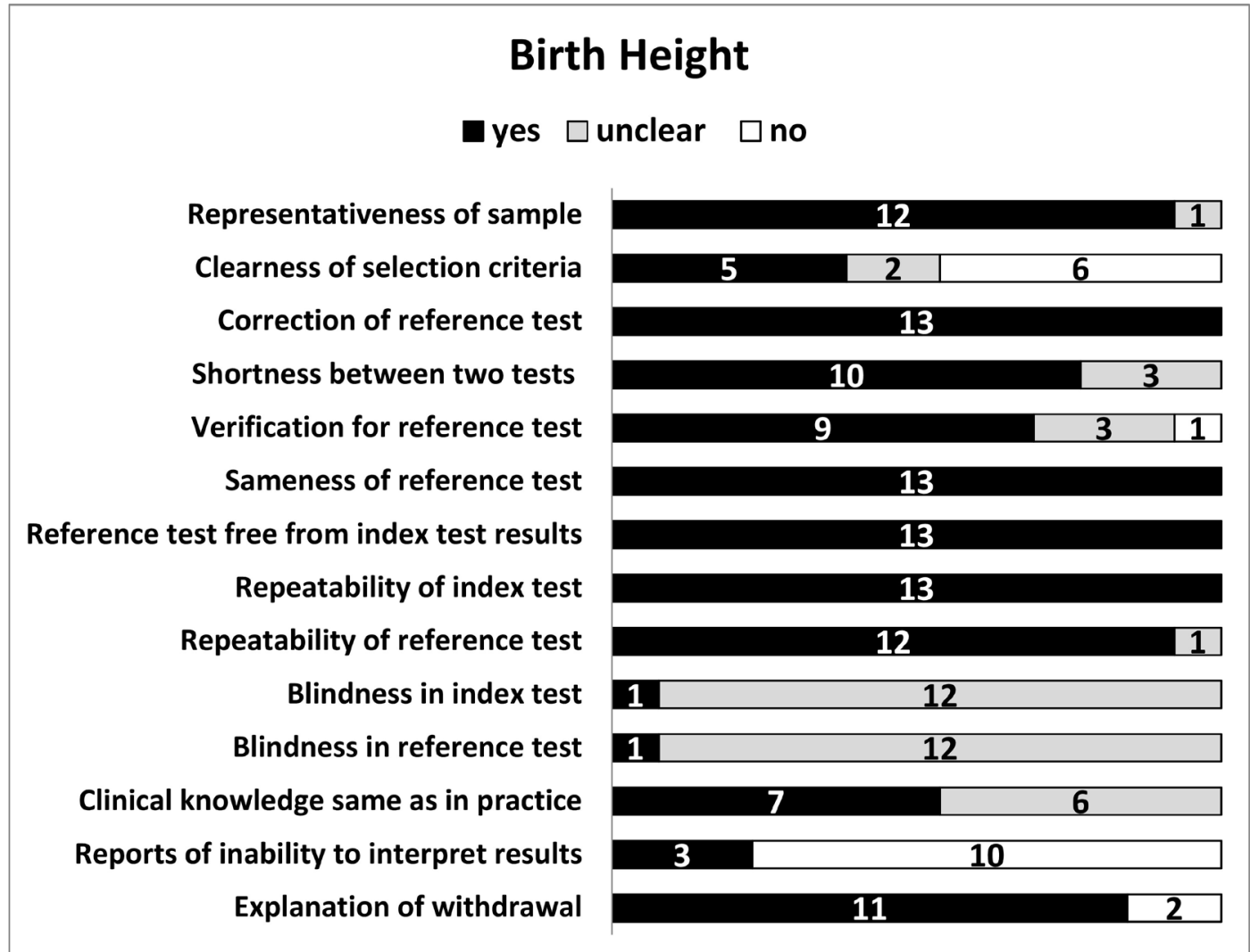

\section{Head Cirumference}

Qyes $\square$ unclear $\square$ no

Representativeness of sample

Clearness of selection criteria

Correction of reference test

Shortness between two tests

Verification for reference test

Sameness of reference test

Reference test free from index test results

Repeatability of index test

Repeatability of reference test

Blindness in index test

Blindness in reference test

Clinical knowledge same as in practice Reports of inability to interpret results

Explanation of withdrawal

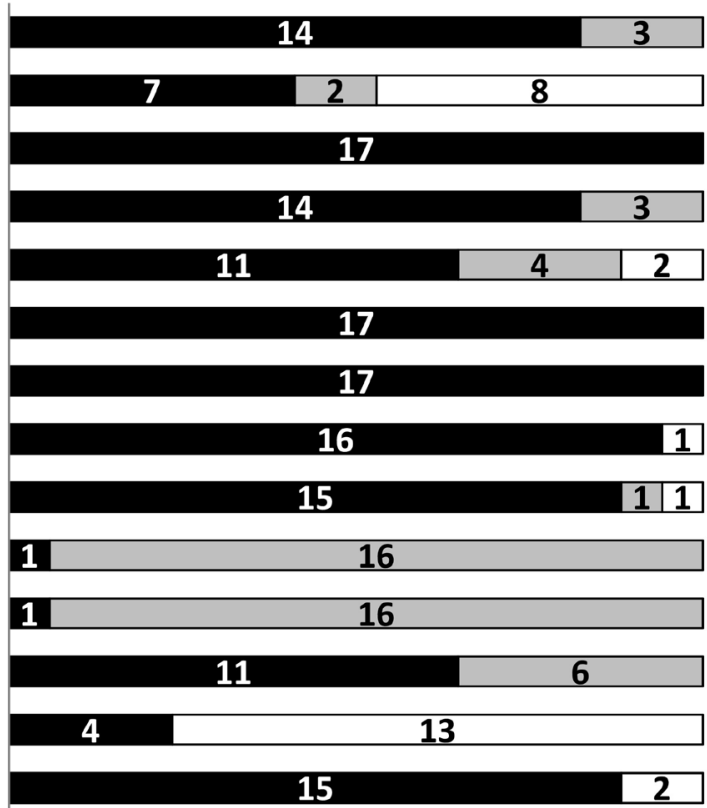




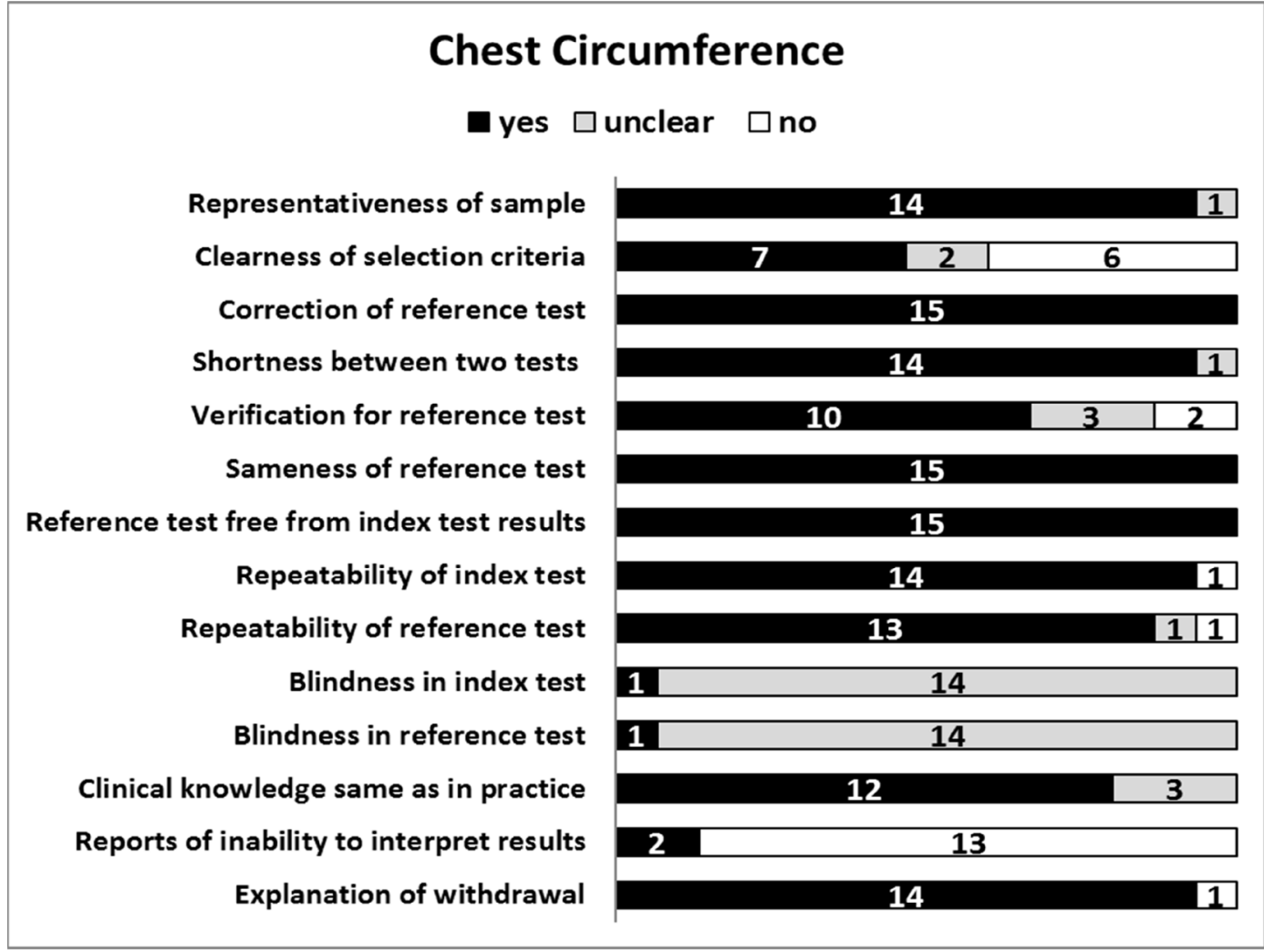

\section{Arm Circumference}

$$
\text { -yes } \square \text { unclear } \square \text { no }
$$

Representativeness of sample

Clearness of selection criteria

Correction of reference test

Shortness between two tests

Verification for reference test

Sameness of reference test

Reference test free from index test results

Repeatability of index test

Repeatability of reference test

Blindness in index test

Blindness in reference test

Clinical knowledge same as in practice

Reports of inability to interpret results

Explanation of withdrawal

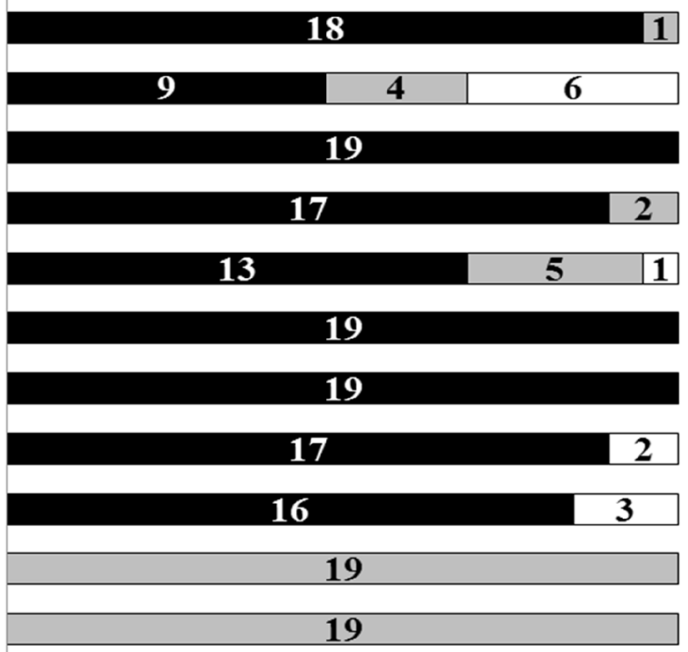

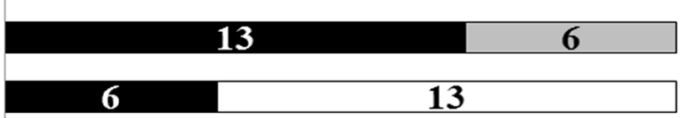

16

Figure 2. Results of study quality assessment using the Quality Assessment of Diagnostic Accuracy Studies. Longer black and gray bars (i.e., more "yes" and "unclear" responses) relative to shorter white bars (i.e., fewer "no" responses) indicate the overall good quality of the included studies, which supports internal validity (i.e., the findings were subject to no serious bias). 


\begin{tabular}{|c|c|}
\hline Arisoy [1995] & $48.0(48.0,48.1)$ \\
\hline Ayatollahi [2002] (Male) & $46.6(46.2,46.9)$ \\
\hline Ayatollahi [2002] (Female) & $46.9(46.6,47.2)$ \\
\hline Ayatollahi [2007] (Male) & $48.3(48.2,48.3)$ \\
\hline Ayatollahi [2007] (Female) & $48.0(47.9,48.1)$ \\
\hline Bhatia $[1984]$ & $47.5(47.4,47.6)$ \\
\hline Das [2005] & $48.1(48.1,48.1)$ \\
\hline De Vaquera [1983] & $46.5(46.5,46.6)$ \\
\hline Dhar [2002] & $46.3(46.2,46.4)$ \\
\hline Dusitsin [1991] & $47.2(47.0,47.3)$ \\
\hline Ezeaka [2003] & $47.3(47.3,47.4)$ \\
\hline Mohan [1990 and 91] & $46.9(46.9,46.9)$ \\
\hline Olusanya $[2010]$ & $45.9(45.9,46.0)$ \\
\hline Overall $(\mathrm{I}$-squared $=99.9 \%, p=0.000)$ & $47.2(46.7,47.7)$ \\
\hline NOTE: Weights are from random effects analysis & \\
\hline
\end{tabular}

\section{Head Circumference}

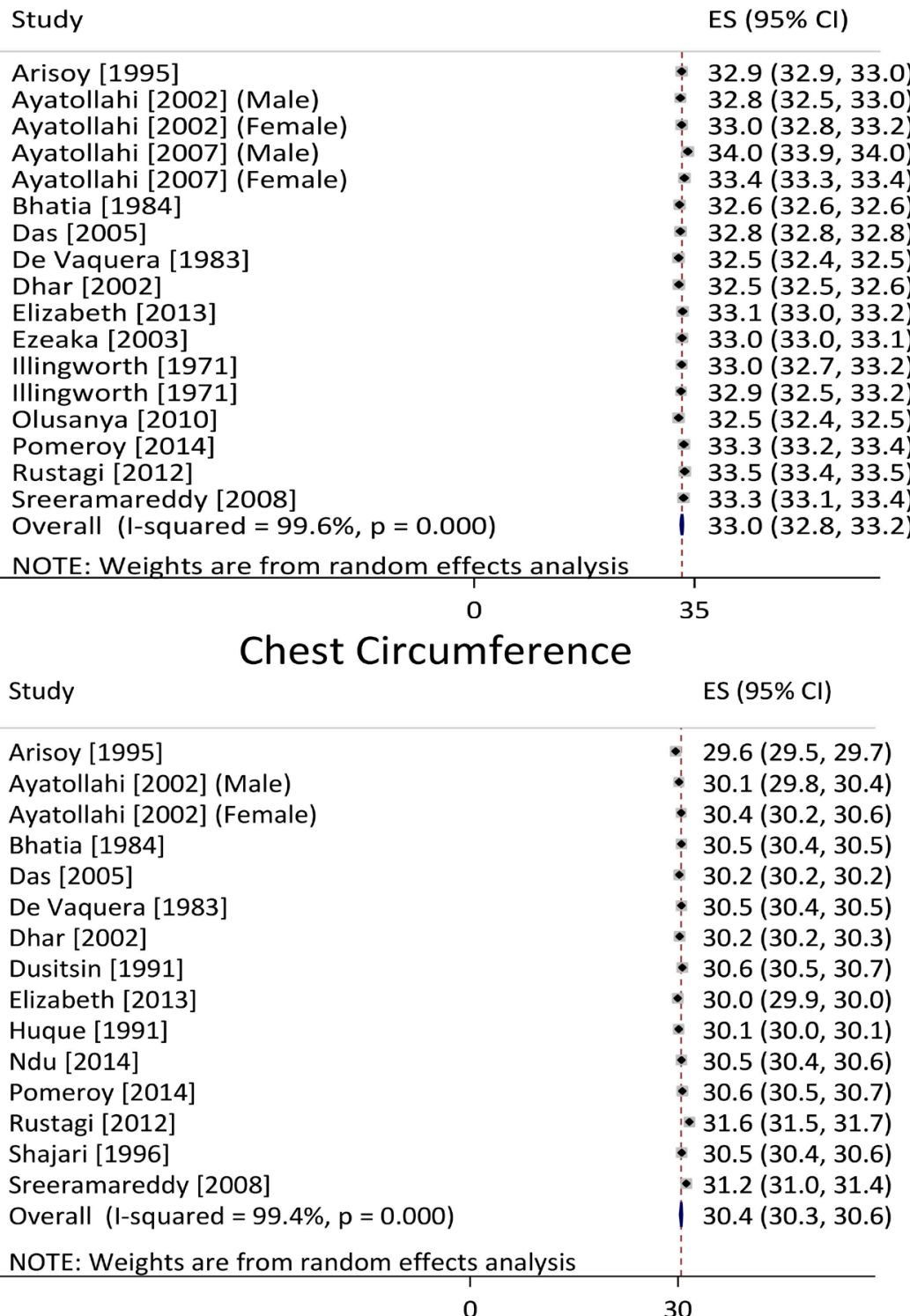




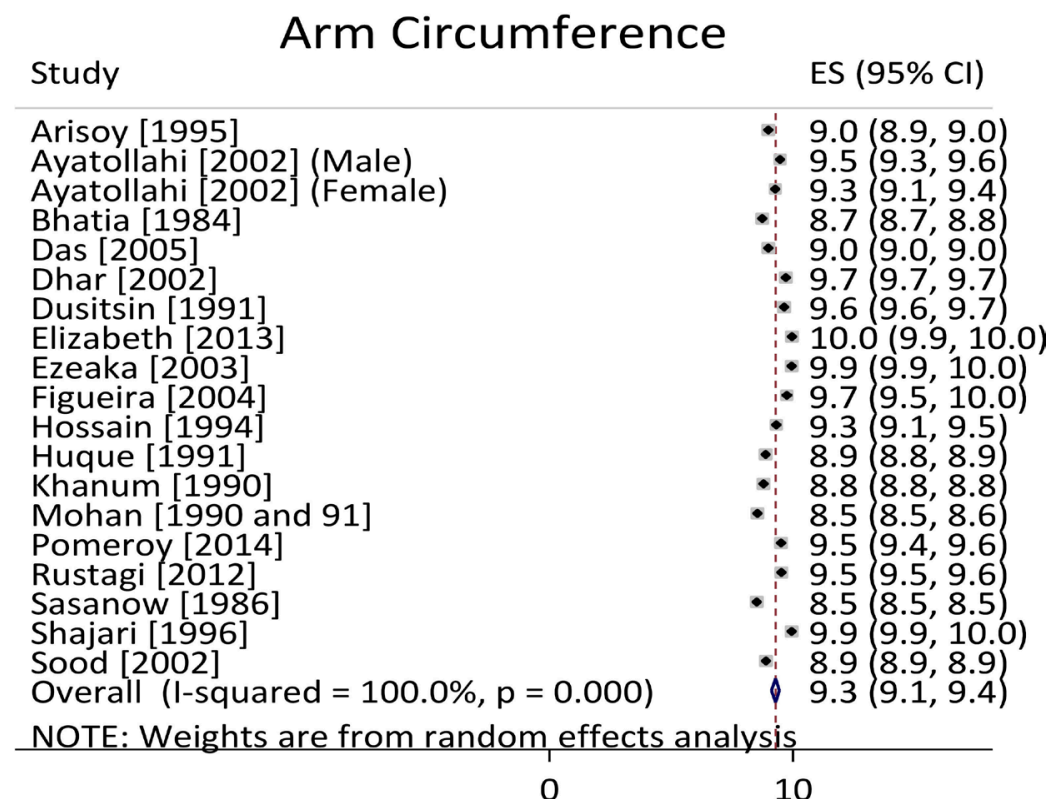

Figure 3. Forest plots to summarize the cut-off points of head, chest and arm circumferences to identify low birthweight. ES, effect size (i.e., summarized cut-off point).

\subsection{Interpretation}

It was impossible to clarify the sources of heterogeneity. Homogeneity was achieved from the heterogeneous data used to summarize the cut-off points of head circumference only by limiting to Europe, but such a limitation included only three studies two of which were extracted from the same article (Table 2).

On the other hand, the sources of heterogeneity and covariates did not seriously affect the interpretation of the results as follows. The cross-country similarities in fetal growth and birth size indicated in the INTERGROWTH-21st Project [26] reflects that the cut-off points of birth height and head, chest, and arm circumferences were similar between the total population vs. individual studies or subgroups (Figure 3 and Table 2). In addition, study region or country vs. other regions or countries was not a covariate in this study (Table 2). It was also not shown that QUADAS score $\geq 10$ vs. $<10$ or males vs. females is a covariate.

\subsection{Strengths and Weaknesses}

One strength of this study was the overall accordance in procedures between this study and the guidelines for conducting meta-analyses [27] [28]. The study procedures included formulating a research question, determining the study design, selecting the studies, extracting the data, performing statistical analysis, interpreting the findings, and drafting the manuscript.

Another strength was the accordance in optimal cut-off points between this and another studies. Based on the Youden indices on summary receiver characteristic operating curves, the cut-off points of chest and arm circumferences were previously estimated to be $29.5-30.5 \mathrm{~cm}$ and $8.5-9.5 \mathrm{~cm}$, respectively, to identify low birthweight [2]. 
Table 2. Summarized cut-off points in total population and subgroups.

\begin{tabular}{|c|c|c|c|c|c|}
\hline Category & $\begin{array}{c}\text { Cut-off } \\
\text { point }(\mathrm{cm})\end{array}$ & $(95 \% \mathrm{CI})$ & $\mathrm{I}^{2}(\%)$ & Meta-regression & Egger test \\
\hline \multicolumn{6}{|l|}{ Birth height } \\
\hline Total population $(n=13)$ & 47.2 & $(46.7-47.7)$ & 99.9 & - & 0.03 \\
\hline Asia $(n=5)$ & 47.2 & $(46.5-47.9)$ & 100.0 & 1.00 & 0.15 \\
\hline The Middle East $(n=4)$ & 47.5 & $(47.0-47.9)$ & 98.2 & 0.46 & 0.08 \\
\hline $\operatorname{Iran}(n=4)$ & 47.5 & $(47.0-47.9)$ & 98.2 & 0.46 & 0.08 \\
\hline Developing countries $(n=13)$ & 47.2 & $(46.7-47.7)$ & 99.9 & - & 0.03 \\
\hline QUADAS $\geq 10(n=6)$ & 47.1 & $(46.4-47.9)$ & 100.0 & 0.71 & 0.09 \\
\hline QUADAS $<10(n=7)$ & 47.3 & $(46.8-47.8)$ & 99.6 & 0.71 & 0.84 \\
\hline \multicolumn{6}{|l|}{ Head circumference } \\
\hline Total population $(n=17)$ & 33.0 & $(32.8-33.2)$ & 99.6 & - & 0.20 \\
\hline Africa $(n=3)$ & 32.9 & $(32.5-33.3)$ & 98.9 & 0.57 & 0.95 \\
\hline Asia $(n=5)$ & 32.9 & $(32.7-33.1)$ & 99.4 & 0.68 & 0.74 \\
\hline Europe $(n=3)$ & 32.9 & $(32.9-33.0)$ & 0.0 & 0.76 & 0.65 \\
\hline The Middle East $(n=4)$ & 33.3 & $(32.8-33.7)$ & 99.2 & 0.10 & 0.49 \\
\hline $\operatorname{Iran}(n=4)$ & 33.3 & $(32.8-33.7)$ & 99.2 & 0.10 & 0.49 \\
\hline Developing countries $(n=14)$ & 33.0 & $(32.8-33.2)$ & 99.7 & 0.81 & 0.35 \\
\hline Developed countries $(n=3)$ & 33.1 & $(32.8-33.4)$ & 77.6 & 0.81 & 0.98 \\
\hline Males $(n=3)$ & 33.2 & $(32.4-34.1)$ & 98.6 & 0.72 & 0.16 \\
\hline Females $(n=3)$ & 33.1 & $(32.8-33.5)$ & 92.3 & 0.72 & 0.21 \\
\hline QUADAS $\geq 10(n=6)$ & 32.8 & $(32.6-33.0)$ & 99.4 & 0.09 & 0.46 \\
\hline QUADAS $<10(n=11)$ & 33.1 & $(32.8-33.5)$ & 99.4 & 0.09 & 0.48 \\
\hline \multicolumn{6}{|l|}{ Chest circumference } \\
\hline Total population $(n=15)$ & 30.4 & $(30.3-30.6)$ & 99.4 & - & 0.05 \\
\hline Asia $(n=7)$ & 30.6 & $(30.4-30.9)$ & 99.6 & 0.17 & 0.07 \\
\hline The Middle East $(n=3)$ & 30.4 & $(30.2-30.6)$ & 73.0 & 0.77 & 0.23 \\
\hline Bangladesh $(n=3)$ & 30.2 & $(30.1-30.2)$ & 85.6 & 0.29 & 0.86 \\
\hline Developing countries $(n=14)$ & 30.4 & $(30.3-30.6)$ & 99.4 & 0.74 & 0.07 \\
\hline QUADAS $\geq 10(n=10)$ & 30.4 & $(30.3-30.6)$ & 99.3 & 0.37 & 0.17 \\
\hline QUADAS $<10(n=5)$ & 29.1 & $(28.4-29.7)$ & 97.5 & 0.37 & 0.80 \\
\hline \multicolumn{6}{|l|}{ Arm circumference } \\
\hline Total population $(n=19)$ & 9.3 & $(9.1-9.4)$ & 100.0 & - & 0.82 \\
\hline Asia $(n=9)$ & 9.1 & $(8.9-9.3)$ & 99.9 & 0.08 & 0.78 \\
\hline The Middle East $(n=4)$ & 9.5 & $(9.1-9.9)$ & 97.0 & 0.32 & 0.01 \\
\hline Bangladesh $(n=4)$ & 9.1 & $(8.8-9.4)$ & 99.9 & 0.39 & 0.77 \\
\hline India $(n=5)$ & 9.6 & $(8.6-9.2)$ & 99.9 & 0.10 & 0.23 \\
\hline $\operatorname{Iran}(n=3)$ & 9.6 & $(9.1-10.0)$ & 97.4 & 0.28 & 0.07 \\
\hline Developing countries $(n=17)$ & 9.3 & $(9.1-9.5)$ & 99.9 & 0.41 & 0.38 \\
\hline QUADAS $\geq 10(n=10)$ & 9.3 & $(9.1-9.5)$ & 99.9 & 0.94 & 0.93 \\
\hline QUADAS < $10(n=9)$ & 9.3 & $(8.9-9.7)$ & 100.0 & 0.94 & 0.07 \\
\hline
\end{tabular}

CI, confidence interval; QUADAS, Quality Assessment of Diagnostic Accuracy Studies. 
The other strengths of this study were: (a) external validity supported by including large numbers of participants in various populations that were extracted from relatively sufficient numbers of studies and (b) internal validity supported by limiting to the inclusion of good quality (i.e., QUADAS score $\geq 8$ ) studies.

Weaknesses of this meta-analysis included that only a single person was involved in reviewing studies and assessing study quality, and there was no contact with the authors to examine the raw data. However, the article selection process was repeated periodically to prevent missing articles, and study quality assessment was repeated five times to increase the reliability of the assessment.

Another weakness was the limitation to extrapolate the results to groups that were not included in this analysis or for which there were too low numbers of studies to support generalizability of the findings. These groups included preterm or full term newborns, small for gestational age or appropriate for gestational age, intrauterine growth retardation, multiple births, and unhealthy newborns.

In addition, the inclusion of more studies with higher quality would provide more optimal cut-off points. For example, studies in which the index test was blind to the results of the reference standard and vice versa would eliminate or minimize bias that may still be latent in this study.

\section{Conclusion}

The conclusions of this meta-analysis and meta-regression are significant for people in the community, health professionals, and public health policy-makers. The optimal cut-off points to identify low birthweight are $33.0 \mathrm{~cm}$ (95\% CI, 32.9 - 32.8), $30.4 \mathrm{~cm}$ (95\% CI, 30.3 - 30.6), and $9.3 \mathrm{~cm}$ (95\% CI, 9.1 - 9.4) for head, chest, and arm circumferences, respectively.

\section{Acknowledgements}

The author wishes to thank the staff of the Medical Library, Japan Medical Association (Tokyo, Japan), for help in retrieving the full texts of the collected articles. English language usage was checked by Dolphin Corporation (1005 Kichijyoji Nagatami City Plaza 1-20-1 Kichijyoji Honmachi. Musashino, 180-0004, Japan, trust@dolphin-tr.com).

\section{Disclosure}

The author declares no conflict of interest.

\section{References}

[1] World Health Organization (2014) Feto-Maternal Nutrition and Low Birth Weight. http://www.who.int/nutrition/topics/feto_maternal/en/

[2] Goto, E. (2011) Meta-Analysis: Identification of Low Birth Weight by Other Anthropometric Measurements at Birth in Developing Countries. Journal of Epidemiology, 21, 354-362. https://doi.org/10.2188/jea.JE20100182

[3] Goto, E. (2011) Meta-Analysis to Estimate the Correlation Coefficients between 
Birth Weight and Other Anthropometric Measurements at Birth. Indian Journal of Pediatrics, 78, 311-318. https://doi.org/10.1007/s12098-010-0288-6

[4] Goto, E. (2015) Evaluation of Anthropometric Measurements at Birth in Predicting Birth Weight Less than $2000 \mathrm{~g}$ in African and Asian Newborns: A Meta-Analysis. Revue d' Epidémiologie et de Santé Publique, 63, 43-49.

[5] Whiting, P., Rutjes, A.W., Reitsma, J.B., Bossuyt, P.M. and Kleijnen, J. (2003) The Development of QUADAS: A Tool for the Quality Assessment of Studies of Diagnostic Accuracy Included in Systematic Reviews. BMC Medical Research Methodology, 3, 25. https://doi.org/10.1186/1471-2288-3-25

[6] Hariss, R.J. and Braburn, M.J. (2008) Metan: Fixed- and Random-Effects MetaAnalysis. The Stata Journal, 8, 3-28.

[7] Harbord, R.M. and Higgins, J.P.T. (2008) Meta-Regression in Stata. The Stata Journal, 8, 493-519.

[8] Egger, M., Davey Smith, G. and Minder, C. (1997) Bias in Meta-Analysis Detected by a Simple, Graphical Test. BMJ, 315, 629-634.

https://doi.org/10.1136/bmj.315.7109.629

[9] Mohan, M., Prasad, SR., Chellani, H.K. and Kapani, V. (1990) Intrauterine Growth Curves in North Indian Babies: Weight, Length, Head Circumference and Ponderal Index. Indian Pediatrics, 27, 43-51.

[10] Mohan, M., Chellani, H.K., Prasad, S.R. and Kapani, V. (1991) Intrauterine Growth Predictors. Indian Pediatrics, 28, 1299-1304.

[11] Bhatia, B.D. and Tyagi, N.K. (1984) Birth Weight: Relationship with Other Fetal Anthropometric Parameters. Indian Pediatrics, 21, 833-838.

[12] Das, J.C., Afroze, A., Khanam, S.T. and Paul, N. (2005) Mid-Arm Circumference: an Alternative Measure for Screening Low Birth Weight Babies. Bangladesh Medical Research Council Bulletin, 31, 1-6.

[13] Elizabeth, N.L., Christopher, O.G. and Patrick, K. (2013) Determining an Anthropometric Surrogate Measure for Identifying Low Birth Weight Babies in Uganda: A Hospital-Based Cross Sectional Study. BMC Pediatrics, 13, 54.

https://doi.org/10.1186/1471-2431-13-54

[14] Ezeaka, V.C., Egri-Okwaji, M.T., Renner, J.K. and Grange, A.O. (2003) Anthropometric Measurements in Detection of Low Birth Weight Infants in Lagos. Nigerian Postgraduate Medical Journal, 10, 168-172.

[15] Ho, T.Y., Ou, S.F., Huang, S.H., et al. (2009) Assessment of Growth from Foot Length in Taiwanese Neonates. Pediatrics \& Neonatology, 50, 287-290.

[16] Huque, F. and Hussain, A.M. (1991) Detection of Low Birth-Weight New Born Babies by Anthropometric Measurements in Bangladesh. Indian Journal of Pediatrics, 58, 223-231. https://doi.org/10.1007/BF02751125

[17] Rustagi, N., Prasuna, J.G. and Taneja, D.K. (2012) Anthropometric Surrogates for Screening of Low Birth Weight Newborns: A Community-Based Study. Asia Pacific Journal of Public Health, 24, 343-351. https://doi.org/10.1177/1010539510384717

[18] Sachar, R.K., Soni, R.K., Afzal, T., Singh, H., Grewal, J. and Sofat, R. (1994) Calf Circumference as Birth Weight Surrogate. Indian Journal of Maternal \& Child Health, 5, 39-40.

[19] Sachar, R.K., Soni, R.K., Afzal, T., Singh, H. and Sofat, R. (1994) Efficacy of Colour Coded Strips for Classifying Birth Weights. Indian Journal of Maternal \& Child Health, 5, 36-38.

[20] Sachar, R.K., Soni, R.K., Grewal, J.S. and Sofat, R. (1994) A Simple Approach for Estimating Birth Weight in Developing Countries. Indian Journal of Maternal \& Child 
Health, 5, 33-35.

[21] Sharma, J.N., Sharma, B.S., Gupta, M.L., Saxena, S. and Sharma, U. (1986) Mid-Arm Circumference at Birth as a Predictor of Low Birth Weight Babies and Early Neonatal mortality. Indian Pediatrics, 23, 915-919.

[22] Sharma, J.N., Saxena, S. and Sharma, U. (1988) Relationship between Birth Weight and Other Neonatal Anthropometric Parameters. Indian Pediatrics, 25, 244-248.

[23] Sharma, J.N., Saxena, S. and Sharma, U. (1989) Thigh Circumference at Birth as the Best Predictor of Low Birth Weight Babies. Indian Pediatrics, 26, 18-21.

[24] Sharma, J.N., Saxena, S. and Sharma, U. (1990) Standard Curves for Mid Arm Circumference and Mid-Arm/Head Circumference Ratio in Newborns. Indian Journal of Pediatrics, 57, 389-393. https://doi.org/10.1007/BF02727922

[25] Sreeramareddy, C.T., Chuni, N., Patil, R., Singh, D. and Shakya, B. (2008) Anthropometric Surrogates to Identify Low Birth Weight Nepalese Newborns: A Hospital-Based Study. BMC Pediatrics, 25, 8-16.

[26] Villar, J., Papageorghiou, A.T., Pang, R., et al. (2014) The Likeness of Fetal Growth and Newborn Size Across Non-Isolated Populations in the Intergrowth-21st Project: The Fetal Growth Longitudinal Study and Newborn Cross-Sectional Study. The Lancet Diabetes \& Endocrinology, 2, 781-792.

[27] Egger, M., Smith, G.D. and Altman, D.G. (2001) Systematic Reviews in Healthcare: Meta-Analysis in Context. 2nd Edition, BMJ, London.

https://doi.org/10.1002/9780470693926

[28] Centre for Reviews and Dissemination (2009) Systematic Reviews: CRD's Guidance for Undertaking Reviews in Health Care. Centre for Reviews and Dissemination. York Publishing Service Ltd., New York. http://www.york.ac.uk/media/crd/Systematic_Reviews.pdf

\section{Submit or recommend next manuscript to SCIRP and we will provide best} service for you:

Accepting pre-submission inquiries through Email, Facebook, LinkedIn, Twitter, etc. A wide selection of journals (inclusive of 9 subjects, more than 200 journals)

Providing 24-hour high-quality service

User-friendly online submission system

Fair and swift peer-review system

Efficient typesetting and proofreading procedure

Display of the result of downloads and visits, as well as the number of cited articles

Maximum dissemination of your research work

Submit your manuscript at: http://papersubmission.scirp.org/

Or contact ojepi@scirp.org 